\title{
Development of a Certified Reference Material (NMIJ CRM 7531-a) for the Determination of Trace Cadmium and Other Elements in Brown Rice Flour
}

\author{
Shin-ichi Miyashita, ${ }^{\dagger}$ Kazumi Inagaki, Tomohiro Narukawa, Yanbei Zhu, Takayoshi Kuroiwa, \\ Akiharu HıOKI, and Koichi CHIBA
}

Environmental Standards Section, National Metrology Institute of Japan (NMIJ), National Institute of Advanced Industrial Science and Technology (AIST), 1-1-1 Umezono, Tsukuba, Ibaraki 305-8563, Japan

\begin{abstract}
A certified reference material (CRM) for trace cadmium and other elements in brown rice flour was developed at the National Metrology Institute of Japan (NMIJ). The CRM was provided as a dry powder after drying and frozen pulverization of fresh brown rice obtained from a Japanese domestic market. Characterization of the property value for each element was carried out exclusively by NMIJ with at least two independent analytical methods, including inductively coupled plasma mass spectrometry (ICP-MS), ICP high-resolution mass spectrometry, isotope-dilution ICP-MS, ICP optical emission spectrometry, and graphite-furnace atomic-absorption spectrometry. Property values were provided for six elements $(\mathrm{Mn}, \mathrm{Fe}, \mathrm{Cu}, \mathrm{Zn}, \mathrm{As}$, and $\mathrm{Cd})$. The concentration range of the property values was from $0.280 \mathrm{mg} \mathrm{kg}^{-1} \mathrm{of}^{-}$ As to $31.8 \mathrm{mg} \mathrm{kg}^{-1}$ of $\mathrm{Zn}$. The combined relative standard uncertainties of the property values were estimated by considering the uncertainties of the homogeneity, characterization, difference among analytical methods, dry-mass correction factor, and calibration standard. The range of the relative combined standard uncertainties was from $1.1 \%$ of $\mathrm{Zn}$ to $1.6 \%$ of As.
\end{abstract}

(Received July 25, 2012; Accepted November 2, 2012; Published December 10, 2012)

\section{Introduction}

The National Metrology Institute of Japan (NMIJ), one of the units of the National Institute of Advanced Industrial Science and Technology (AIST), provides a wide variety of certified reference materials (CRMs) that are certified for trace element and elemental speciation analysis. ${ }^{1}$ The NMIJ CRMs were produced based on the NMIJ's management system in compliance with the International Organization for Standardization (ISO) Guide $34: 2009^{2}$ and ISO/the International Electrotechnical Commission (IEC) 17025:2005. ${ }^{3}$

Cadmium $(\mathrm{Cd})$ exerts toxic effects on the kidney, the skeletal, and the respiratory systems, and is classified as a human carcinogen. ${ }^{4}$ Since low concentrations of $\mathrm{Cd}$ are found in vegetables, cereals, and starchy roots, human exposure occurs mainly from the consumption of contaminated food. ${ }^{4}$ In east and south-east Asia, for example, $\mathrm{Cd}$ in daily foods accounts for more than $95 \%$ of the total body burden. ${ }^{5}$ In Japan, dietary Cd exposure of general populations without occupational exposure to the element have been estimated to be (25 to 30$) \mu \mathrm{g}$ day $^{-1}$, of which rice accounts for up to $50 \%{ }^{6}$ According to a report released by the Joint FAO/WHO Expert Committee on Food Additives (JECFA), ${ }^{7}$ the mean value of dietary Cd exposure for Japanese adults $\left(24 \mu \mathrm{g} \mathrm{day}^{-1}\right)$ is higher than those of USA Lebanon, and four Asia-Pacific rim countries ((4 to 14) $\mu \mathrm{g} \mathrm{day}^{-1}$ of Australia to $20 \mu \mathrm{g} \mathrm{day}^{-1}$ of China) and of the European

† To whom correspondence should be addressed.

E-mail: shinichi-miyashita@ aist.go.jp region, including 16 countries $\left(18 \mu \mathrm{g} \mathrm{day}^{-1}\right)$, assuming $60 \mathrm{~kg}$ body weight. In South Korea, rice is an essential food with up to $61 \%$ of total cereal consumption, and the estimated daily intake of $\mathrm{Cd}$ by the rice was $5.38 \mu \mathrm{g} \mathrm{day}^{-1}$, assuming rice consumption of $256 \mathrm{~g} \mathrm{day}^{-1}$ by the overall households. ${ }^{8}$ Thus, rice is not only an essential food, but also a major dietary source of $\mathrm{Cd}$ burden for general Japanese and Korean populations. In European countries, rice consumption had increased from 1990 to 2004 due to immigration and diversification of the diet of the Europeans; this trend would presumably continue in the next years, although rice is not a staple food for most of the European population. ${ }^{9}$

In 2006, Joint FAO/WHO Codex Alimentarius Commission (hereafter Codex) administered jointly by the Food and Agriculture Organization of the United Nations (FAO) and World Health Organization (WHO) set the maximum permissible level (MPL) for Cd in white (polished) rice at $0.4 \mathrm{mg} \mathrm{kg}^{-1}$ fresh weight (fw), ${ }^{10}$ and are in the process of setting the MPL for As in white rice. In 2008 and 2009, NMIJ produced white rice CRMs (NMIJ CRM 7501-a, 7502-a, 7503-a) ${ }^{1}$ corresponding to the Codex standard, and they have been widely and continuously distributed. In addition to white rice, brown (unpolished) rice is one of the major cereals consumed in many countries, including Japan, and it has been much more frequently analyzed, mostly in testing laboratories for food safety management, when compared with white rice. For that reason, proper CRMs are required for quality control of the analysis, evaluation or validation of analytical methods. However, there is currently no distributed brown rice CRM; the preexisting brown rice standard reference material (NIES No. 10) distributed from National 
Institute for Environmental Studies (NIES) is a set of three kinds of brown-rice samples that have different certified values of Cd concentrations (low, $0.023 \mu \mathrm{g} \mathrm{g}^{-1}$ dry weight (dw); middle, $0.32 \mu \mathrm{g} \mathrm{g}^{-1} \mathrm{dw}$; high, $1.82 \mu \mathrm{g} \mathrm{g}^{-1} \mathrm{dw}$ ), and each sample has certified values of 13-element concentrations ( $\mathrm{Na}, \mathrm{Mg}, \mathrm{P}, \mathrm{K}$, $\mathrm{Ca}, \mathrm{Mn}, \mathrm{Fe}, \mathrm{Ni}, \mathrm{Cu}, \mathrm{Zn}, \mathrm{Rb}, \mathrm{Mo}$, and $\mathrm{Cd}$ ) and reference values of nine-element concentrations ( $\mathrm{B}, \mathrm{Al}, \mathrm{Cl}, \mathrm{Cr}, \mathrm{Co}, \mathrm{As}, \mathrm{Se}, \mathrm{Sr}$ and $\mathrm{Hg}$ ), but this series of samples has been discontinued. In addition, the existing white rice CRMs are undesirable for precise quantification of the elements in a brown-rice sample, due to the large difference of their matrices. Thus, there is a growing need for a brown rice CRM.

In this paper, the authors present a detailed analysis for the certification of $\mathrm{Cd}$, As, and four essential mineral elements (Mn, $\mathrm{Fe}, \mathrm{Cu}$, and $\mathrm{Zn}$ ) in a brown rice CRM (NMIJ CRM 7531-a), which can be used for the determination of the elements in brown rice flour or similar matrices for environmental monitoring, food safety management, and other relavant purposes.

\section{Experimental}

\section{Preparation of the candidate CRM}

Approximately $30 \mathrm{~kg}$ of fresh brown rice, whose average $\mathrm{Cd}$ concentration and coefficient of variation (homogeneity) had been confirmed to be $c a$. $0.3 \mathrm{mg} \mathrm{kg}^{-1}$ and $\leq 15 \% \quad(n=6)$, respectively, were obtained from a domestic market. The fresh brown rice was dried at $60^{\circ} \mathrm{C}$ for $8 \mathrm{~h}$, and then frozen pulverized. The brown rice flour was dried again at $60^{\circ} \mathrm{C}$ for $8 \mathrm{~h}$ and divided into approximately 3-g subsamples; then, 640 sets of six subsamples were built by stratified random sampling and packed into respective labeled amber glass bottles $(50 \mathrm{~mL}$, approximately $20 \mathrm{~g}$ of brown rice flour each). The bottles were vacuum sealed in individual transparent plastic bags. Finally, the candidate CRM was sterilized with $\gamma$-ray irradiation ( $c a .20 \mathrm{kGy})$. It should be noted that the bottles were prewashed in detergent and pure water with ultrasound each for $1 \mathrm{~h}$, dried at $60^{\circ} \mathrm{C}$ with a UV clean dryer, and labeled with continuous numbers for management.

\section{Instrumentation}

Determinations of the elemental concentration in brown-rice samples were carried out with an inductively coupled plasma mass spectrometry (ICP-MS: Agilent 7700x; Agilent Technologies, Tokyo, Japan), an ICP high-resolution mass spectrometry (ICP-HRMS: Element 2; Thermo Fisher Scientific, Yokohama, Japan), an ICP optical emission spectrometry (ICP-OES: Optima 7300 DV; PerkinElmer Japan, Yokohama, Japan), and a graphite-furnace atomic-absorption spectrometry (GF-AAS: AAnalyst 800, PerkinElmer Japan; Unicam Solaar 989QZ, Thermo Fisher Scientific). The operating condition of each instrument was optimized daily. A microwave digestion system, ETHOS One (Milestone General K.K., Kawasaki, Japan), was used for acid digestion of the samples.

The measurands chosen for determining the elemental concentrations are summarized in Table 1. In ID-ICP-MS measurements, a double-IDMS method ${ }^{11}$ was applied. In ID-ICP-MS, ICP-MS, ICP-HRMS, and ICP-OES measurements, an internal standard method was applied. A mixture of standard solutions of $\mathrm{Co}, \mathrm{Y}$, and $\mathrm{Rh}$ was added to each sample and calibration standard solution at the final concentration of $10 \mu \mathrm{g} \mathrm{kg}^{-1}$, and an appropriate element(s) among them was monitored as an internal standard. A calibration curve of each element was composed of four concentration points, including
Table 1 Summary of monitored ions and wavelengths for target species of the instruments

\begin{tabular}{ll}
\hline \multicolumn{1}{c}{ Instrument } & \multicolumn{1}{c}{ Monitored ion or wavelength } \\
\hline ID-ICP-MS & ${ }^{56} \mathrm{Fe} /{ }^{57} \mathrm{Fe},{ }^{63} \mathrm{Cu} /{ }^{65} \mathrm{Cu},{ }^{66} \mathrm{Zn} /{ }^{67} \mathrm{Zn},{ }^{114} \mathrm{Cd} /{ }^{111} \mathrm{Cd}$ \\
ICP-MS & ${ }^{55} \mathrm{Mn},{ }^{56} \mathrm{Fe},{ }^{59} \mathrm{Co},{ }^{65} \mathrm{Cu},{ }^{66} \mathrm{Zn},{ }^{75} \mathrm{As},{ }^{89} \mathrm{Y},{ }^{103} \mathrm{Rh},{ }^{111} \mathrm{Cd},{ }^{185} \mathrm{Re}$ \\
ICP-HRMS & ${ }^{59} \mathrm{Co},{ }^{75} \mathrm{As}(\mathrm{HR}),{ }^{89} \mathrm{Y}$ \\
ICP-OES & $\mathrm{Mn} 257.61 \mathrm{~nm}, \mathrm{Fe} 238.204 \mathrm{~nm}, \mathrm{Y} 371.03 \mathrm{~nm}$ \\
GF-AAS & $\mathrm{Mn} 279.5 \mathrm{~nm},{ }^{\mathrm{c}} \mathrm{As} 193.7 \mathrm{~nm}^{\mathrm{d}}$ \\
\hline
\end{tabular}

a. HR, high-resolution $(m / \Delta m 10000)$; elements without notation were measured at medium resolution $(\mathrm{m} / \Delta m$ 3000).

b. Axial observation.

c. Measured by Unicam Solaar 989QZ.

d. Measured by AAnalyst 800 .

zero. To minimize the uncertainty in the calibration curve, the elemental concentrations in the samples were adjusted to approximately the concentration present at the middle of the calibration curve. In GF-AAS measurements, a calibration method was applied. A calibration curve was made similarly to ICP measurements.

\section{Chemicals}

Ultrapure-grade water used throughout this experiment was prepared using a Millipore purification system (Element; Nihon Millipore Kogyo K.K., Tokyo, Japan).

For obtaining property values, single-element standards (guaranteed by the Japan Calibration Service System, JCSS; $1000 \mathrm{mg} \mathrm{L}^{-1}$ ) were purchased from Kanto Chemical Co., Inc. (Tokyo, Japan), and used for the gravimetric preparation of standard solutions. The following reagents were also purchased from Kanto Chemical: $\mathrm{HNO}_{3}, \mathrm{HF}, \mathrm{H}_{2} \mathrm{O}_{2}$, and $\mathrm{HClO}_{4}$ (ultrapure grade) for digestion of the brown-rice samples and for making solutions; $\mathrm{HNO}_{3}$ and $\mathrm{HCl}$ (electronic grade) for cleaning of sample bottles, pipette tips, and digestion vessels.

The following spikes were used in ID-ICP-MS: ${ }^{57} \mathrm{Fe}(96.44 \%)$, ${ }^{65} \mathrm{Cu}(99.70 \%),{ }^{67} \mathrm{Zn}(94.60 \%)$, and ${ }^{111} \mathrm{Cd}(92.88 \%)$ from the Oak Ridge National Laboratory (NT, USA). A white rice CRM (NMIJ CRM 7502-a) was used to validate the analytical methods.

\section{Cleaning of sample bottles, pipette tips, and digestion vessels}

Polypropylene sample bottles and single-use Eppendorf micropipette tips were used throughout the experiment. Prior to the experiment, all sample bottles and pipette tips were cleaned by soaking in a $3 \mathrm{~mol} \mathrm{~L}^{-1} \mathrm{HNO}_{3}$ solution for one week, followed by rinsing five times with pure water in a laboratory room. The PTFE digestion vessels were cleaned with a TraceCLEAN system (Milestone General; $450^{\circ} \mathrm{C}, 5 \mathrm{~h}$ ) employing $50 \%$ aqua regia, followed by rinsing six times with pure water.

\section{Optimization of oven-drying conditions}

The optimum oven-drying conditions were examined as follows. Approximately $1.0 \mathrm{~g}$ of the sample was weighed in a glass vessel, and heated in an oven at various conditions $\left(85-105^{\circ} \mathrm{C}\right.$ for $\left.10-16 \mathrm{~h}\right)$. After that, the sample was cooled in a desiccator with silica gel for $30 \mathrm{~min}$, followed by weighing. The dry-mass correction factor was calculated as the ratio of the sample masses before and after drying. The optimum ovendrying condition was decided to be a condition that the drymass correction factors of oven-drying and drying in a desiccator with phosphorus pentoxide, which can absorb only moisture in the sample, were satisfactorily in agreement with each other. 
In the case of drying in a desiccator with phosphorus pentoxide, approximately $1.0 \mathrm{~g}$ of the sample was weighed in a glass vessel, and left in a desiccator for at least one week until a change in the sample mass was confirmed to be $\leq 0.1 \%$, followed by weighing and calculating the dry-mass correction factor.

\section{Microwave-assisted acid digestion}

All of the property values were determined after microwave acid digestion of the sample with the dry-mass correction. The optimized microwave digestion procedure was obtained by modifying that used in our previous development of white rice CRMs. ${ }^{1}$ Microwave acid digestion using $\mathrm{HNO}_{3}$ with additionally $\mathrm{HF}$ and $\mathrm{H}_{2} \mathrm{O}_{2}$ (hereafter acid mixture 1) was mainly performed for measurements by ICP-MS and GF-AAS. In addition, $\mathrm{HNO}_{3}$ with additionally $\mathrm{HF}$ and $\mathrm{HClO}_{4}$ (hereafter acid mixture 2) was also used for digestion of the sample prior to the measurements by ID-ICP-MS, ICP-HRMS, and ICP-OES, for the purpose of cross validation of microwave acid digestions. HF was added for complete digestion of brown-rice samples, because large number of studies had shown that the complete digestion of plant samples (including $0.1-10 \%$ of silica) ${ }^{12}$ was accomplished by the addition of a small volume of HF. ${ }^{13-18}$

The detailed sample-digestion procedures using acid mixture 1 for measurements by ICP-MS and GF-AAS were as follows. Approximately $0.5 \mathrm{~g}$ of the sample was precisely balanced and put into the digestion vessel, followed by adding $7 \mathrm{~mL}$ of $\mathrm{HNO}_{3}$. The digestion vessel was immediately sealed, and then left overnight. Next, the sample was subjected to the first step of microwave irradiation (ramp to $150^{\circ} \mathrm{C}$ over $30 \mathrm{~min}$, hold for $20 \mathrm{~min}$ ). After cooling down, $0.5 \mathrm{~mL}$ of $\mathrm{HF}$ and $2 \mathrm{~mL}$ of $\mathrm{H}_{2} \mathrm{O}_{2}$ were further added into the sample, which was then subjected to the second step of microwave irradiation (ramp to $220^{\circ} \mathrm{C}$ over $30 \mathrm{~min}$, hold for $20 \mathrm{~min}$ ). After cooling, the acid solution in the digestion vessel was evaporated to dryness or a small droplet on a hot plate on a clean bench, and then $1.0 \mathrm{~mL}$ of $\mathrm{HNO}_{3}$ and approximately $5 \mathrm{~mL}$ of pure water were added into the digestion vessel to dissolve the digested sample. Finally, approximately $50 \mathrm{~g}$ of the digested sample solution was obtained by adding pure water. The digested sample solution obtained was further diluted properly for measurements.

In the case of sample digestion with acid mixture 2 for measurements by ID-ICP-MS, ICP-HRMS, and ICP-OES, approximately $0.5 \mathrm{~g}$ of the sample was precisely balanced and put into the digestion vessel, and then $5 \mathrm{~mL}$ of $\mathrm{HNO}_{3}$ was added. In the case of ID-ICP-MS, an enriched isotope spike, whose amount was properly adjusted to minimize the uncertainty of analytical method, was added immediately after balancing the sample. The digestion vessel was immediately sealed, and then left overnight. After that, the sample was subjected to the first step of microwave irradiation (ramp to $150^{\circ} \mathrm{C}$ over $30 \mathrm{~min}$, hold for $20 \mathrm{~min}$ ). After cooling down, $0.5 \mathrm{~mL}$ of $\mathrm{HF}$ and $1 \mathrm{~mL}$ of $\mathrm{HClO}_{4}$ were further added into the sample, which was then subjected to the second step of microwave irradiation (ramp to $220^{\circ} \mathrm{C}$ over $30 \mathrm{~min}$, hold for $20 \mathrm{~min}$ ). Thereafter, the digested sample solution was treated similarly to acid mixture 1 .

A blank test was also carried out parallel to the sample in each batch of microwave acid digestion, where a volume of acid equivalent to that used in the sample was added into a blank digestion vessel, and subjected to the same digestion procedure together with the samples.

\section{Homogeneity test and stability test}

A homogeneity test was carried out following the ISO Guide 35:2006. ${ }^{19}$ Ten bottles (at least three subsamples of approximately $0.5 \mathrm{~g}$ for each bottle) of the candidate CRM material were digested by microwave acid digestion using a mixture of $\mathrm{HNO}_{3}, \mathrm{HF}$, and $\mathrm{H}_{2} \mathrm{O}_{2}$, and subjected to measurements by ICP-MS with the internal standard method, as in the case of the determination of the property value by ICP-MS. An analysis of the variance (ANOVA) was carried out for the results, and the obtained within-bottle mean square $\left(M S_{\text {within }}\right)$ and between-bottle mean square $\left(M S_{\text {among }}\right)$ were applied in Eqs. (1) and (2) to obtain the between-bottle variance $\left(s_{\mathrm{bb}}\right)$ and the possible between-bottle variance estimated from the influence of analytical repeatability $\left(u_{\mathrm{bb}}\right)$, respectively:

$$
\begin{aligned}
& S_{\mathrm{bb}}=\left(\left(M S_{\text {among }}-M S_{\text {within }}\right) / n\right)^{0.5}, \\
& u_{\mathrm{bb}}=\left(M S_{\text {within }} / n\right)^{0.5} \cdot\left(2 / \nu_{\mathrm{MS}_{\text {within }}}\right)^{0.25} .
\end{aligned}
$$

In Eq. (2), $n$ is the harmonized mean of analyzed subsample number, and $v_{\mathrm{MS}_{\text {within }}}$ the degree of freedom of $M S_{\text {within. }}$ Regarding the within-bottle variance, the uncertainty of quantitative analysis was defined as the relative residual standard deviation $(s)$ of the signal intensities when the standard solutions were analyzed for drawing a calibration curve in the ICP-MS measurement, and the square of $s$ was subtracted from $M S_{\text {within; }}$; consequently, the square root of the resultant was evaluated as the standard uncertainty of the within-bottle variance $\left(u_{\text {in-b) }}\right)$. If $s$ was larger than the square root of $M S_{\text {within, }}$, the within-bottle variance was ignored. Larger values of $s_{\mathrm{bb}}$ and $u_{\mathrm{bb}}$ and $u_{\mathrm{in}-\mathrm{b}}$ were combined and used as the contribution of homogeneity to the combined standard uncertainty of the property value.

The candidate CRM material was presumed to be stable for 15 years, judging from (1) the results of the long-term (five years) stability test of our white rice CRMs ${ }^{1}$ similarly prepared as this material and (2) the analytical results of preexisting brown rice CRMs (NIES No. 10 series; more than 15 years passed from the beginning of their distributions). Finally, the candidate CRM material was decided to be valid for seven years on appropriate preserving conditions (ambient temperature of $\leq 30^{\circ} \mathrm{C}$, shaded clean space).

Long-term stability monitoring will be carried out during the period in which the present CRM is in service.

\section{Uncertainty estimation in instrumental measurement}

Uncertainty estimations of the results obtained by instrumental analysis were carried out following the JCGM 100:2008 (GUM 1995 with minor corrections). ${ }^{20}$ The uncertainties of homogeneity, dry-mass correction factor, and calibration standard were not considered for uncertainty estimations of the analytical results because the uncertainty factors were included in the uncertainty of the property values.

In a calibration method of instrumental determination, the uncertainty was estimated based on a spreadsheet approach considering all of the factors in Eqs. (3) and (4):

$$
\begin{aligned}
& c_{\mathrm{x}}=c_{\mathrm{cal}} \cdot r \cdot m_{\mathrm{sol}} \cdot m_{\mathrm{dil}} /\left(d \cdot m_{\mathrm{x}} \cdot m_{\mathrm{sol}}^{\prime}\right)-c_{\mathrm{blk}}, \\
& c_{\mathrm{cal}}=\left(y_{\mathrm{A}}-b\right) / a,
\end{aligned}
$$

where $c_{\mathrm{x}}$ is the elemental concentration $\left(\mathrm{g} \mathrm{g}^{-1}\right)$ in the candidate CRM material; $c_{\text {cal }}$, the elemental concentration $\left(\mathrm{g} \mathrm{g}^{-1}\right)$ in the diluted sample solution subjected to the measurement; $d$, the dry-mass correction factor obtained as the ratio (dry mass)/(wet mass); $r$, the reproducibility factor of sample preparation including microwave acid digestion; $m_{\mathrm{sol}}$, the mass $(\mathrm{g})$ of the sample solution after digestion; $m_{\mathrm{dil}}$, the mass $(\mathrm{g})$ of the sample after dilution; $m_{\mathrm{x}}$, the mass $(\mathrm{g})$ of the candidate CRM material used for digestion; $m_{\text {sol }}^{\prime}$, the mass $(\mathrm{g})$ of the digested sample 
solution taken for obtaining the diluted sample solution for measurement; $c_{\mathrm{blk}}$, the method blank $\left(\mathrm{g} \mathrm{g}^{-1}\right) ; y_{\mathrm{A}}$, the signal intensity obtained from the measurement; $a$ and $b$, slope and intercept, respectively, of the calibration curve. The uncertainty of $c_{\text {cal }}\left(u_{\text {cal }}\right)$ was calculated by combining the uncertainties of the calibration curve and $y_{\mathrm{A}}\left(u_{\mathrm{y}_{\mathrm{A}}}\right.$, standard errors of measured values); the former was regarded as the standard uncertainties of $a$ and $b$ ( $u_{\mathrm{a}}$ and $u_{\mathrm{b}}$, respectively), both of which were obtained from the partial differential equation of the linear-regression line $\left(y_{\mathrm{i}}=a x_{\mathrm{i}}+b ; x_{\mathrm{i}}\right.$, elemental concentration of calibration standard), and the covariance of $a$ and $b\left(u_{\mathrm{a}, \mathrm{b}}\right)$. The symbols of $m_{\mathrm{sol}}, m_{\mathrm{sol}}^{\prime}$, $m_{\mathrm{dil}}$, and $m_{\mathrm{x}}$ were the masses weighed by the electric balance (recordable up to $0.1 \mathrm{mg}$ ); their uncertainties were estimated from the linearity and sensitivity of the balance. The uncertainty of $r$ was obtained as the average of the relative standard deviation of three-sample analysis of each bottle. The uncertainty of $c_{\mathrm{blk}}$ was regarded as the standard error of the blank value.

Following the EURACHEM/CITAC Guide CG $4,{ }^{21}$ an uncertainty estimation for ID-ICP-MS was calculated based on a spreadsheet approach, which considered all of the factors in Eq. (5), the symbols of which are explained with $\mathrm{Cd}$ as the analyte:

$$
\begin{aligned}
c_{\mathrm{x}}=c_{\mathrm{z}} \cdot r \cdot \frac{m_{\mathrm{y}}}{d \cdot m_{\mathrm{x}}} \cdot \frac{m_{\mathrm{z}}}{m_{\mathrm{y}}^{\prime}} \cdot \frac{K_{\mathrm{y}} \cdot R_{\mathrm{y}}-K_{\mathrm{b}} \cdot R_{\mathrm{b}}}{K_{\mathrm{b}} \cdot R_{\mathrm{b}}-K_{\mathrm{x}} \cdot R_{\mathrm{x}}} \cdot \frac{K_{\mathrm{b}^{\prime}} \cdot R_{\mathrm{b}^{\prime}}-K_{\mathrm{z}} \cdot R_{\mathrm{z}}}{K_{\mathrm{y}} \cdot R_{\mathrm{y}}-K_{\mathrm{b}^{\prime}} \cdot R_{\mathrm{b}^{\prime}}} \\
\\
\frac{\sum\left(K_{\mathrm{xi}} \cdot R_{\mathrm{xi}}\right)}{\sum\left(K_{\mathrm{zi}} \cdot R_{\mathrm{zi}}\right)}-c_{\mathrm{blk}} .
\end{aligned}
$$

In Eq. (5), subscripts $x, y, z, b$, and $b^{\prime}$ represent the sample, the isotope-enriched spike, the standard, the blend solution of $\mathrm{x}$ and $\mathrm{y}$ for ID, and the blend solution of $\mathrm{y}$ and $\mathrm{z}$ for reverse ID, respectively; $c_{\mathrm{x}}$ and $c_{\mathrm{z}}$, concentrations of $\mathrm{Cd}\left(\mathrm{mol} \mathrm{g}^{-1}\right)$ in $\mathrm{x}$ and $\mathrm{z}$, respectively; $r$, reproducibility factor; $m_{\mathrm{x}}$ and $m_{\mathrm{y}}$, masses of $\mathrm{x}$ and y (g) in blend $\mathrm{b}$, respectively; $d$, dry-mass correction factor; $m_{\mathrm{y}}^{\prime}$ and $m_{\mathrm{z}}$, masses of y and $\mathrm{z}(\mathrm{g})$ in blend $\mathrm{b}^{\prime}$, respectively; $R_{\mathrm{x}}$, $R_{\mathrm{z}}, R_{\mathrm{b}}$, and $R_{\mathrm{b}^{\prime}}$, measured ratios of ${ }^{114} \mathrm{Cd} /{ }^{111} \mathrm{Cd}$ in $\mathrm{x}, \mathrm{z}, \mathrm{b}$, and $\mathrm{b}^{\prime}$, respectively; $R_{\mathrm{y}}$, calculated ratio of ${ }^{114} \mathrm{Cd} /{ }^{111} \mathrm{Cd}$ in y based on the certificate of the ${ }^{111} \mathrm{Cd}$-enriched spike; $\sum\left(K_{\mathrm{xi}} \cdot R_{\mathrm{xi}}\right)$ and $\sum\left(K_{\mathrm{zi}} \cdot R_{\mathrm{zi}}\right)$, reciprocal of the isotopic abundance of the denominator $\left({ }^{111} \mathrm{Cd}\right)$ of ${ }^{114} \mathrm{Cd} /{ }^{111} \mathrm{Cd}$ ratio obtained from IUPAC isotopic abundance (representative value); ${ }^{22} K_{\mathrm{x}}, K_{\mathrm{z}}, K_{\mathrm{b}}$, and $K_{\mathrm{b}^{\prime}}$, mass bias correction factor of $R_{\mathrm{x}}, R_{\mathrm{z}}, R_{\mathrm{b}}$, and $R_{\mathrm{b}^{\prime}}$, respectively; $K_{\mathrm{y}}$, mass bias correction factor of $R_{\mathrm{y}}$ being set to 1 because of difficulty in accurately measuring the ratio of ${ }^{114} \mathrm{Cd} /{ }^{111} \mathrm{Cd}$ of the ${ }^{111} \mathrm{Cd}$-enriched spike solution; $c_{\text {blk }}$, method blank $\left(\mathrm{mol} \mathrm{g}^{-1}\right) . K_{\mathrm{z}}$ was regarded as the reciprocal of the value obtained from dividing the measured ratio of ${ }^{114} \mathrm{Cd} /{ }^{111} \mathrm{Cd}$ of the $\mathrm{Cd}$ standard solution by its calculated ratio from IUPAC isotopic abundance (representative value). ${ }^{22}$ Each individual value of $K_{\mathrm{x}}, K_{\mathrm{b}}$, and $K_{\mathrm{b}^{\prime}}$ was decided from the $K_{\mathrm{z}}$ values, which were measured before and after each measurement of the isotope ratios $R_{\mathrm{x}}, R_{\mathrm{b}}$, and $R_{\mathrm{b}^{\prime}}$. The symbols $m_{\mathrm{x}}, m_{\mathrm{y}}, m_{\mathrm{y}}^{\prime}$, and $m_{\mathrm{z}}$ are the masses weighed by an electric balance, and their uncertainties were similarly obtained as in a calibration method of instrumental measurement. The standard uncertainty of $K_{\mathrm{z}}$ was regarded as the standard error of $K_{\mathrm{z}}$. When we estimate the uncertainty of $K_{\mathrm{z}}$, we did not include the uncertainty from IUPAC isotopic abundance, because its uncertainty was common to $K_{\mathrm{x}}, K_{\mathrm{b}}$, and $K_{\mathrm{b}^{\prime}}$. The uncertainties of $R_{\mathrm{x}}, R_{\mathrm{z}}, R_{\mathrm{b}}$, and $R_{\mathrm{b}^{\prime}}$ were regarded as standard errors of the measured ratios. The uncertainty of $R_{\mathrm{y}}$ was calculated from the uncertainties of the abundances of ${ }^{111} \mathrm{Cd}$ and ${ }^{114} \mathrm{Cd}$, based on the certificate of the ${ }^{111} \mathrm{Cd}$-enriched spike. The uncertainties of $\sum\left(K_{\mathrm{xi}} \cdot R_{\mathrm{xi}}\right)$ and $\sum\left(K_{\mathrm{zi}} \cdot R_{\mathrm{zi}}\right)$, which were regarded as independent uncertainty sources from each other, were calculated from the standard

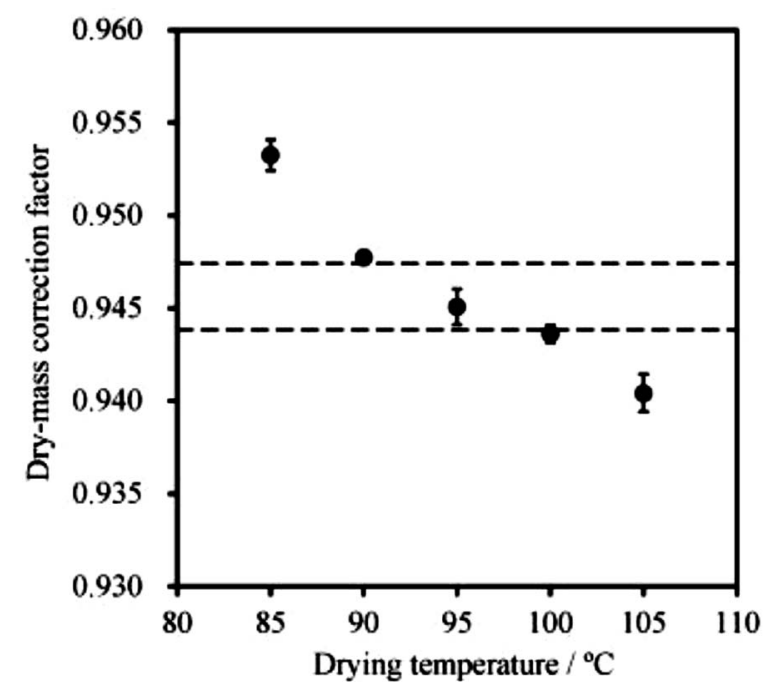

Fig. 1 Results of examinations for optimizing the oven-drying conditions. Approximately $1.0 \mathrm{~g}$ of the candidate CRM material was heated in an oven at $85-105^{\circ} \mathrm{C}$ for $12 \mathrm{~h}$. The dashed lines indicate the upper and lower values of the dry-mass correction factor (mean \pm standard deviation, $n=3$ ) obtained from drying samples in a desiccator with phosphorus pentoxide.

uncertainties of the IUPAC isotopic abundance. ${ }^{22}$ The calculations for the uncertainties of $r$ and $c_{\mathrm{blk}}\left(u_{\mathrm{r}}\right.$ and $u_{\mathrm{cbl}}$, respectively) were done similarly to the calibration method.

\section{Results and Discussion}

\section{Optimum oven-drying conditions}

The property values for the elements in the candidate CRM were determined based on the dry-mass, similarly to the white rice $\mathrm{CRMs}^{1}$ previously produced by NMIJ. Versatile drying techniques include drying in a desiccator with a hygroscopic agent, such as phosphorus pentoxide or magnesium perchlorate, and oven-drying. Drying in a desiccator with a hygroscopic agent is a more reproducible method. However, it takes approximately 10 days to obtain a dry-mass correction factor by this method, and the highly reactive agents needed are often dangerous to users. Oven-drying enables rapid evaporation of moisture in a sample due to its high temperature, and is thus convenient for the users. However, oven-drying often undesirably evaporates organic molecules contained in the sample as well as water molecules, indicating that the setting of drying temperature is quite important.

Considering user's convenience, the determination of the drymass correction factor was performed by an oven-drying method, parallel to each batch of microwave acid digestion. The dry-mass correction factors of the candidate CRM material were investigated by heating approximately $1.0 \mathrm{~g}$ of the material in an oven at $85-105^{\circ} \mathrm{C}$ for $10-16 \mathrm{~h}$; the results from heating for $12 \mathrm{~h}$ are shown in Fig. 1. The dry-mass correction factor obtained by $95^{\circ} \mathrm{C}$ for $12 \mathrm{~h}$ was $0.9489 \pm 0.0013$ (mean \pm standard deviation, $n=10$ ), which was equivalent to those obtained by drying in desiccators with phosphorus pentoxide for at least one week, which means that only moisture in the sample was removed by heating in an oven. In addition, the variation in the factors for 10 and $16 \mathrm{~h}$ were within the uncertainty of the factor for $12 \mathrm{~h}$. Thus, the optimum oven-drying conditions for the candidate $\mathrm{CRM}$ were decided to be $95^{\circ} \mathrm{C}$ for $12-16 \mathrm{~h}$. 
Table 2 Analytical results of the elements in NMIJ CRM 7502-a (mean \pm expanded uncertainty, $k=2$ ) (unit: $\mathrm{mg} \mathrm{kg}^{-1}$ )

\begin{tabular}{|c|c|c|c|c|c|c|}
\hline Method & $\mathrm{Mn}$ & $\mathrm{Fe}$ & $\mathrm{Cu}$ & $\mathrm{Zn}$ & As & $\mathrm{Cd}$ \\
\hline ID-ICP-MS & & $4.405 \pm 0.004$ & $2.99 \pm 0.03$ & $26.1 \pm 0.1$ & & $0.5510 \pm 0.0004$ \\
\hline $\mathrm{ICP}^{-\mathrm{MS}^{\mathrm{b}}}$ & 11.2 & 4.47 & 3.01 & 26.1 & 0.112 & 0.547 \\
\hline ICP-HRMS $^{\mathrm{a}}$ & & & & & $0.109 \pm 0.004$ & \\
\hline ICP-OES ${ }^{\mathrm{a}}$ & 11.0 & 4.35 & 3.01 & 26.7 & & 0.556 \\
\hline GF-AAS ${ }^{b}$ & $11.0 \pm 0.4$ & & & & $0.109 \pm 0.001$ & \\
\hline Certified value & $11.2 \pm 0.4$ & $4.48 \pm 0.20$ & $3.02 \pm 0.11$ & $26.0 \pm 0.9$ & $0.109 \pm 0.005$ & $0.548 \pm 0.020$ \\
\hline
\end{tabular}

a. One sample was measured four times for ID-ICP-MS, twice for ICP-HRMS, and once for ICP-OES. b. One sample was measured once for ICP-MS and six times for GF-AAS.

Table 3 Results of homogeneity test

\begin{tabular}{|c|c|c|c|c|c|c|}
\hline \multirow{2}{*}{ Element } & \multirow{2}{*}{$n$} & \multicolumn{2}{|c|}{$\begin{array}{c}\text { Between-bottle } \\
\text { variance, } \%\end{array}$} & \multicolumn{3}{|c|}{ Within-bottle variance, $\%$} \\
\hline & & $s_{\mathrm{bb}}$ & $u_{\mathrm{bb}}$ & $M S_{\text {within }}{ }^{0.5}$ & $s$ & $u_{\text {in-b }}$ \\
\hline $\mathrm{Mn}$ & 3.43 & 0.03 & 0.09 & 0.33 & 0.43 & - \\
\hline $\mathrm{Fe}$ & 3.43 & 0.34 & 0.28 & 0.96 & 0.37 & 0.89 \\
\hline $\mathrm{Cu}$ & 3.43 & 0.13 & 0.12 & 0.41 & 0.62 & - \\
\hline $\mathrm{Zn}$ & 3.43 & - & 0.11 & 0.37 & 0.61 & - \\
\hline As & 3.43 & 0.62 & 0.34 & 1.18 & 1.38 & - \\
\hline $\mathrm{Cd}$ & 3.43 & 0.20 & 0.20 & 0.68 & 0.35 & 0.59 \\
\hline
\end{tabular}

\section{Validation of methods}

A white rice CRM (NMIJ CRM 7502-a) was analyzed by ID-ICP-MS, ICP-MS, ICP-HRMS, ICP-OES, and GF-AAS to check the validity of the present method; the results are summarized in Table 2. The present results were in agreement with the certified values. Thus, the present methods were regarded to be valid for measuring the elements in brown-rice samples.

\section{Results of homogeneity test}

The results of homogeneity tests are summarized in Table 3. The larger values of $s_{\mathrm{bb}}$ and $u_{\mathrm{bb}}$ in bold font and $u_{\mathrm{in}-\mathrm{b}}$ were combined and regarded as the contribution of the homogeneity to the combined standard uncertainty.

In a comparison to the combined standard uncertainties, the uncertainty factors due to homogeneity were small enough so that the candidate CRM could be considered to be adequately homogeneous.

\section{Analytical results and property values of the elements}

Analytical results obtained by each method are summarized in Table 4. All of the elements were determined by more than three independent methods.

The analytical results of each element were in agreement with each other within the ranges of their uncertainties so that, based on Eq. (6), the property value of each element was calculated as the weighted mean of the results obtained by every method,

$$
c_{\text {char }}=\left(\sum\left(c_{\mathrm{i}} \cdot w_{\mathrm{i}}\right)\right) /\left(\sum w_{\mathrm{i}}\right),
$$

where $c_{\text {char }}$ is the characterized property value, $c_{\mathrm{i}}$ the concentration obtained by method $\mathrm{i}$, and $w_{\mathrm{i}}$ the weight of method $\mathrm{i}$, where $w_{\mathrm{i}}$ was calculated based on

$$
w_{\mathrm{i}}=1 / u_{\mathrm{i}}
$$

where $u_{\mathrm{i}}$ is the standard uncertainty of method $\mathrm{i}$. The uncertainty of the characterization was calculated based on Eq. (8), and was applied to calculating the combined standard uncertanty of the property value,

$$
u_{\text {char }}^{2}=\sum\left(u_{\mathrm{i}}^{2} \cdot w_{\mathrm{i}}^{2}\right) /\left(\sum w_{\mathrm{i}}\right)^{2} .
$$

\section{Calculation of combined standard uncertainties of property} values

The combined standard uncertainties $\left(u_{\mathrm{CRM}}\right)$ of the property values for the candidate CRM were estimated by combining the contributions of homogeneity $\left(u_{\mathrm{hom}}\right)$, characterization $\left(u_{\text {char }}\right)$, difference among analytical methods $\left(u_{\text {meth }}\right)$, dry-mass correction factor $\left(u_{\text {dry }}\right)$, and calibration standard $\left(u_{\text {std }}\right)$, following the ISO Guide 35:2006. ${ }^{19}$ The short-term and long-term stability uncertainties were not considered in calculating the combined standard uncertainty of the property value because they could be negligibly low when compared to other uncertainties of the property value. The short-term stability could be retained by transporting the CRM at almost the same conditions as the defined preserving conditions (ambient temperature). The long-term stability would be retained within the defined expiration date. The calculation of $u_{\mathrm{CRM}}$ was carried out based on

$$
u_{\mathrm{CRM}^{2}}=u_{\mathrm{hom}}{ }^{2}+u_{\mathrm{char}^{2}}{ }^{2}+u_{\mathrm{meth}^{2}}{ }^{2}+u_{\mathrm{dry}}{ }^{2}+u_{\mathrm{std}}^{2} .
$$

The results of the combined standard uncertainties of the property values are summarized in Table 5 . The values of $u_{\text {hom }}$ were obtained by the homogeneity test. The calculating of $u_{\text {char }}$ was based on Eq. (8). The values of $u_{\text {meth }}$ were obtained from the between-method variance, similar to $s_{\mathrm{bb}}$ in the homogeneity test, based on an ANOVA analysis of the results with all methods given in Table 4. Since the analytical results of $\mathrm{Fe}, \mathrm{Zn}$, and $\mathrm{Cd}$ by different methods closely agreed with each other, their variances were not obtained; consequently, $u_{\text {meth }}$ could be negligible for characterizing the property values of these elements. Since the variation of the dry-mass correction factors obtained by oven-drying at $95^{\circ} \mathrm{C}$ for $12-16 \mathrm{~h}$ by the users of the CRM could potentially be significantly larger than the other uncertainties, $u_{\text {dry }}$ was evaluated as one of the contributions to $u_{\mathrm{CRM}}$ of the property values. Assuming that the maximum variation of the dry-mass correction factor obtained by user can vary because the maximum variation of the temperature in a prevailing oven is $\pm 10^{\circ} \mathrm{C}$, the larger value of the differences between the dry-mass correction factors of $85^{\circ} \mathrm{C}$ and $95^{\circ} \mathrm{C}$ and $95^{\circ} \mathrm{C}$ and $105^{\circ} \mathrm{C}(0.0082$; relative standard uncertainty of $0.87 \%$ ) was applied as $u_{\text {dry }}$. The values of $u_{\text {std }}$ were calculated based on certificate reports of the JCSS standard solutions because the same standard solutions were used in all analytical methods. 
Table 4 Analytical results (mean \pm standard uncertainty) and property values (unit: $\mathrm{mg} \mathrm{kg}^{-1}$ )

\begin{tabular}{lcccccc}
\hline \multicolumn{1}{c}{ Method } & $\mathrm{Mn}$ & $\mathrm{Fe}$ & $\mathrm{Cu}$ & $\mathrm{Zn}$ & $\mathrm{As}$ & $\mathrm{Cd}$ \\
\hline ID-ICP-MS & & $11.62 \pm 0.08$ & $4.32 \pm 0.03$ & $31.8 \pm 0.9$ & & $0.307 \pm 0.002$ \\
ICP-MS & $27.52 \pm 0.12$ & $11.65 \pm 0.07$ & $4.35 \pm 0.02$ & $31.9 \pm 0.2$ & $0.283 \pm 0.004$ & $0.3089 \pm 0.0017$ \\
ICP-HRMS & & & & $0.278 \pm 0.006$ & $0.306 \pm 0.006$ \\
ICP-OES & $27.8 \pm 0.3$ & $11.71 \pm 0.10$ & $4.42 \pm 0.13$ & $31.8 \pm 0.6$ & & $0.278 \pm 0.007$ \\
GF-AAS & $27.9 \pm 0.5$ & 11.66 & 4.34 & 31.8 & 0.280 & 0308 \\
Property value & 27.6 & 1.6 & & & \\
\hline
\end{tabular}

a. The contributions of homogeneity, calibration standard, and dry-mass correction factor were not considered in calculating the standard uncertainty.

Table 5 Budgets of the combined standard uncertainties (relative, \%)

\begin{tabular}{ccccccc}
\hline Element & $u_{\text {hom }}$ & $u_{\text {char }}$ & $u_{\text {meth }}$ & $u_{\text {dry }}$ & $u_{\text {std }}$ & $\begin{array}{c}\text { Combined standard } \\
\text { uncertainty, } u_{\text {CRM }}\end{array}$ \\
\hline $\mathrm{Mn}$ & 0.09 & 0.45 & 0.62 & 0.87 & 0.35 & 1.2 \\
$\mathrm{Fe}$ & 0.96 & 0.42 & - & 0.87 & 0.30 & 1.4 \\
$\mathrm{Cu}$ & 0.14 & 0.48 & 1.06 & 0.87 & 0.30 & 1.5 \\
$\mathrm{Zn}$ & 0.11 & 0.66 & - & 0.87 & 0.30 & 1.1 \\
$\mathrm{As}$ & 0.62 & 1.13 & 0.14 & 0.87 & 0.30 & 1.6 \\
$\mathrm{Cd}$ & 0.62 & 0.58 & - & 0.87 & 0.30 & 1.2 \\
\hline
\end{tabular}

Property values and expanded uncertainties of the elements in NMIJ CRM 7531- $a$

The property values of six elements were characterized in the present CRM. As summarized in Table 6, the property values are shown as $c_{\text {char }} \pm U$ with a covering factor of $k=2$, which corresponds to an estimated confidence interval of approximately $95 \%$.

The order of the property values of $\mathrm{Mn}, \mathrm{Fe}, \mathrm{Cu}, \mathrm{Zn}, \mathrm{As}$, and $\mathrm{Cd}$ from largest to smallest in the present CRM was: $\mathrm{Zn}$ $\left(31.8 \mathrm{mg} \mathrm{kg}^{-1}\right)>\operatorname{Mn}\left(27.6 \mathrm{mg} \mathrm{kg}^{-1}\right)>\mathrm{Fe}\left(11.66 \mathrm{mg} \mathrm{kg}^{-1}\right)>\mathrm{Cu}$ $\left(4.34 \mathrm{mg} \mathrm{kg}^{-1}\right)>\mathrm{Cd}\left(0.308 \mathrm{mg} \mathrm{kg}^{-1}\right)>$ As $\left(0.280 \mathrm{mg} \mathrm{kg}^{-1}\right)$. A similar trend was previously reported in brown rice collected from 22 countries, with the mean values being: $\mathrm{Zn}$ (16.4 mg $\left.\mathrm{kg}^{-1}\right)>\mathrm{Cu}\left(4 \mathrm{mg} \mathrm{kg}^{-1}\right)>\mathrm{Cd}\left(0.029 \mathrm{mg} \mathrm{kg}^{-1}\right) .{ }^{23}$ In addition, the concentrations in brown rice collected nationwide in Japan was in a similar order, with the mean values being: $\mathrm{Mn}\left(26 \mathrm{mg} \mathrm{kg}^{-1}\right)$ $\approx \mathrm{Zn}\left(25 \mathrm{mg} \mathrm{kg}^{-1}\right)>\mathrm{Fe}\left(11 \mathrm{mg} \mathrm{kg}^{-1}\right)>\mathrm{Cu}\left(3 \mathrm{mg} \mathrm{kg}^{-1}\right)>\mathrm{As}$ $\left(0.085 \mathrm{mg} \mathrm{kg}^{-1}\right)>\mathrm{Cd}\left(0.064 \mathrm{mg} \mathrm{kg}^{-1}\right){ }^{24}$ In spite of a similar order of the elemental concentrations in brown rice, the absolute levels of the elements, expecially As and Cd, were different.

It is generally accepted that edible plants grown on uncontaminated or unmineralized soils contain (0.01 to 1.5$)$ $\mathrm{mg} \mathrm{kg}^{-1}$ of As, with leafy vegetables being in the upper range and fruits in the lower range. ${ }^{25}$ The property value of As $\left(0.280 \mathrm{mg} \mathrm{kg}^{-1}\right)$ in the present CRM fell into this nomal range. A previous study demostrated that the background levels of $\mathrm{Cd}$ in cereal grains range from $0.013 \mathrm{mg} \mathrm{kg}^{-1}$ to $0.22 \mathrm{mg} \mathrm{kg}^{-1} .{ }^{26}$ The property value of $\mathrm{Cd}\left(0.308 \mathrm{mg} \mathrm{kg}^{-1}\right)$ in the present CRM did not fall into this nomal range. In addition, it was significantly higher than the Cd levels in brown-rice samples harvested in 1997 - 1998 at 37250 locations in all 47 prefectures in Japan (median, $0.042 \mathrm{mg} \mathrm{kg}^{-1}$; minimum, $0.005 \mathrm{mg} \mathrm{kg}^{-1}$; maximum, $\left.1.2 \mathrm{mg} \mathrm{kg}^{-1}\right){ }^{27}$ However, it was relatively close to the Codex standard of $\mathrm{Cd}\left(0.4 \mathrm{mg} \mathrm{kg}^{-1} \mathrm{fw}\right),{ }^{10}$ which is advantageous, especially for testing laboratoris, to validate the analytical method, and thereby to determine $\mathrm{Cd}$ concentrations near $0.4 \mathrm{mg} \mathrm{kg}^{-1}$ with high accuracy. Thus, this CRM can be regarded as a representative brown-rice sample with an
Table 6 Property values and expanded uncertainties $(U)$ of the elements in NMIJ CRM 7531-a (unit: $\mathrm{mg} \mathrm{kg}^{-1}$ )

\begin{tabular}{cc}
\hline Element & $c_{\text {char }} \pm U(k=2)$ \\
\hline $\mathrm{Mn}$ & $27.6 \pm 0.7$ \\
$\mathrm{Fe}$ & $11.66 \pm 0.32$ \\
$\mathrm{Cu}$ & $4.34 \pm 0.13$ \\
$\mathrm{Zn}$ & $31.8 \pm 0.7$ \\
$\mathrm{As}$ & $0.280 \pm 0.009$ \\
$\mathrm{Cd}$ & $0.308 \pm 0.007$ \\
\hline
\end{tabular}

unusually high concentration of $\mathrm{Cd}$, and can be used for food safety management, as well as method validation, internal quality control, environmental monitoring, and other relavant purposes.

\section{Conclusions}

A brown rice CRM, NMIJ CRM 7531-a (brown rice flour), has been developed by NMIJ. Property values for six elements $(\mathrm{Mn}, \mathrm{Fe}, \mathrm{Cu}, \mathrm{Zn}, \mathrm{As}$, and $\mathrm{Cd}$ ) were provided for the present CRM. The combined standard uncertainties were estimated by combining the contributions of homogeneity, analytical method, characterization, calibration standard, and dry-mass correction factor. This CRM corresponds to the Codex standard, and can be used for determining the elements in brown rice flour or similar matrices for method validation and internal quality control, as well as environmental monitoring, food safety management, and other relavant purposes.

\section{Acknowledgements}

The present authors express sincere gratitude to Mr Alexander S. Groombridge (The University of Sheffield) for preliminary grammatical checking of this manuscript.

\section{References}

1. NMIJ Reference Materials, the National Metrology Institute of Japan, http://www.nmij.jp/english/service/C/, accessed 20 June 2012.

2. ISO Guide 34, "General Requirements for the Competence of Reference Material Producers", 2009, ISO, Geneva.

3. ISO/IEC 17025, "General Requirements for the Competence of Calibration and Testing Laboratories", 2005, ISO/IEC, Geneva.

4. Preventing Disease through Healthy Environments, "Action 
is Needed on Chemicals of Major Public Health Concern", 2010, WHO, Geneva.

5. M. Ikeda, Z. W. Zhang, S. Shimbo, T. Watanabe, H. Nakatsuka, C. S. Moon, N. Matsuda-Inoguchi, and K. Higashikawa, Sci. Total Environ., 2000, 249, 373.

6. T. Watanabe, Z. W. Zhang, C. S. Moon, S. Shimbo, H. Nakatsuka, N. Matsuda-Inoguchi, K. Higashikawa, and M. Ikeda, Int. Arch. Occ. Env. Hea., 2000, 73, 26.

7. Seventy-third Report of the Joint FAO/WHO Expert Committee on Food Additives, "Evaluation of Certain Food Additives and Contaminants", 2011, WHO, Geneva.

8. M. C. Jung, S. T. Yun, J. S. Lee, and J. U. Lee, Environ. Geochem. Health, 2005, 27, 455.

9. A. Ferrero, Cah. Agric., 2007, 16, 4.

10. Codex, Twenty-ninth Session, Joint FAO/WHO Food Standards Programme, 2006, International Conference Centre, Geneva, Switzerland.

11. J. Vogl and W. Pritzkow, Journal of Metrology Society of India, 2010, 25, 135.

12. E. Epstein, Proc. Natl. Acad. Sci. U. S. A., 1994, 91, 11.

13. M. Hoenig, H. Baeten, S. Vanhentenrijk, E. Vassileva, and P. Quevauviller, Anal. Chim. Acta, 1998, 358, 85.

14. R. Koplík, E. Čurdová, and M. Suchánek, Fresenius J. Anal. Chem., 1998, 360, 449.

15. X. B. Feng, S. L. Wu, A. Wharmby, and A. Wittmeier, J. Anal. At. Spectrom., 1999, 14, 936.
16. M. Krachler, C. Mohl, H. Emons, and W. Shotyk, Spectrochim. Acta, Part B, 2002, 57, 1277.

17. X. P. Wang, Spectrosc. Spect. Anal., 2005, 25, 563.

18. J. Sucharova and I. Suchara, Anal. Chim. Acta, 2006, 576, 163.

19. ISO Guide 35, "Reference Materials-General and Statistical Principles for Certification", 2006, ISO, Geneva.

20. JCGM 100, "Evaluation of Measurement Data-Guide to the Expression of Uncertainty in Measurement", 2008, Working Group 1 of the Joint Committee for Guides in Metrology (JCGM/WG 1).

21. EURACHEM/CITAC Guide CG 4, "Quantifying Uncertainty in Analytical Measurement", 2000, Joint EURACHEM/ CITAC Working Group.

22. M. Berglund and M. E. Wieser, Pure Appl. Chem., 2011, 83, 397.

23. R. Masironi, S. R. Koirtyohann, and J. O. Pierce, Sci. Total Environ., 1997, 7, 27.

24. S. Uchida, K. Tagami, and I. Hirai, J. Nucl. Sci. Technol., 2007, 44, 779.

25. H. J. M. Bowen, "Environmental Chemistry of the Elements", 1979, Academic Press, New York, 333.

26. A. Kabata-Pendias, "Trace Elements in Soils and Plants", 3rd ed., 2000, CRC Press, New York, 432.

27. N. Koizumi, F. Ohashi, and M. Ikeda, Int. Arch. Occ. Env. Hea., 2010, 83, 333. 